\title{
Prediction of Creep Deformation in Concrete Using Some Design Code Models
}

\author{
${ }^{1}$ Brian E. Usibe, ${ }^{2}$ Iniobong P. Etim, ${ }^{3}$ James O. Ushie \\ ${ }^{1,2,3}$ Department of Physics University of Calabar Calabar
}

\begin{abstract}
The tendency of a concrete material to deform under stress is often responsible for excessive deflection at service loads which can compromise the performance of elements with a structure. Hence, the realistic prediction of both the magnitude and rate of creep strain is an important requirement of the design process. Therefore, relatively simple empirically based national design Code models are analyzed in order to predict the magnitude of creep strain. The models assessed are ACI 209 (1992), AS 3600 (1988), BS 8110 (1985), CEB-FIP (1978), CEB-FIP (1990), SAB 0100 (1992) and the RILEM Model B3 (1995).
\end{abstract}

Keywords: Creep deformation, concrete, creep strain, design code models.

The Phenomenon of Creep

\section{Introduction}

Creep is the progressive accumulation of plastic strain in a specimen or machine part under the influence of stress over a period of time, leading to slow movement or deformation. It occurs as a result of long exposure to high levels of stress that are below the yield strength of the material.

The rate of deformation is a function of the material properties, exposure time, exposure temperature and the applied structural load.

Creep strain at any time, $\varepsilon_{\mathrm{c}}(\mathrm{t})$ is determined as

$\varepsilon_{\mathrm{c}}(\mathrm{t})=\varepsilon(\mathrm{t})-\varepsilon_{\mathrm{e}}-\varepsilon_{\mathrm{sh}}(\mathrm{t})$

where

$\varepsilon_{\mathrm{c}}(\mathrm{t}) \quad$ is creep strain at any time $\mathrm{t}$

$\varepsilon(\mathrm{t}) \quad$ is the total measured strain at any time $\mathrm{t}$

$\varepsilon_{\mathrm{e}} \quad$ is the average instantaneous elastic strain recorded immediately after loading.

$\varepsilon_{\text {sh }} \quad$ is the drying shrinkage strain at any time $\mathrm{t}$ (determined on unloaded specimen).

Creep strain at any time can be classified as basic or drying creep component. If the concrete is sealed or if there is no moisture exchange between the concrete and the ambient medium, only basic creep occurs. Drying creep is the additional creep experienced when the concrete is allowed to dry while under sustained load. The sum of basic and drying creep is known as total creep.

\section{Stages of Creep}

After instantaneous strain $\varepsilon_{0}$ three regions of creep can be discerned as shown in Fig. 1.

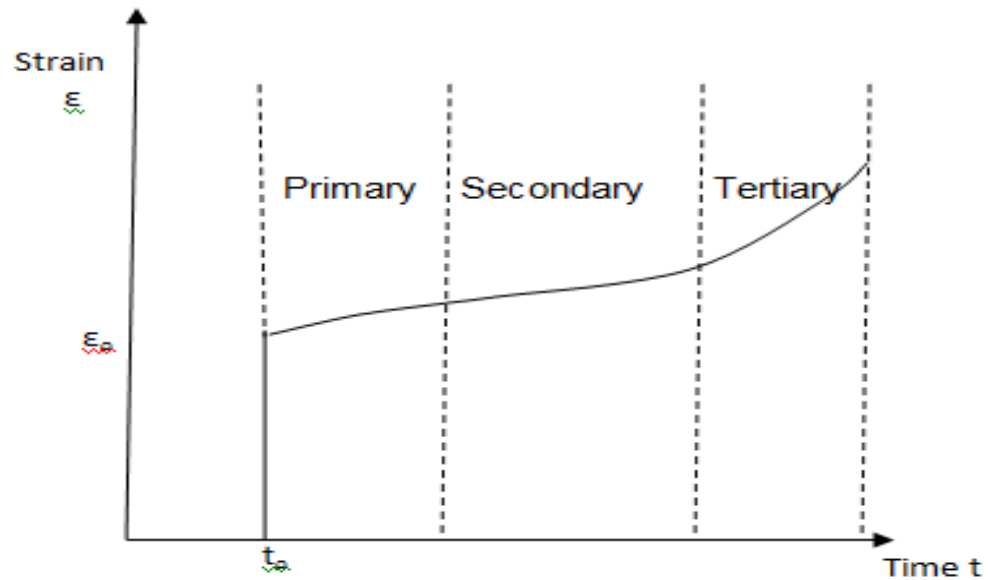

Fig. 1: Strain as a function of time due to constant stress over an extended period.

(i) Primary (transient) creep stage

Here, the rate of extension is relatively high, but decreases with time. 
(ii) Secondary (steady state) creep stage

The strain rate remains almost constant. The slope of the curve at this stage is referred to as the linear creep rate.

(iii) Tertiary stage

The strain rate accelerates exponentially leading to fracture.

The general creep equation is given by

$$
\frac{d \varepsilon}{d t}=\frac{c \delta^{m}}{d^{b}} e^{-Q / K T}
$$

where

$\begin{array}{lll}\varepsilon & = & \text { creep strain } \\ \mathrm{c} & = & \begin{array}{l}\text { a constant dependent on the material and } \\ \text { particular creep mechanism }\end{array} \\ \mathrm{d} & = & \text { grain size of material } \\ \mathrm{Q} & = & \text { activation energy of creep mechanism } \\ \mathrm{m} \& \mathrm{~b} & = & \text { exponents dependent on creep mechanism } \\ \mathrm{T} & = & \text { absolute temperature } \\ \mathrm{K} & = & \text { Boltzmann constant }\left(1.38 \times 10^{-23} \mathrm{~J} / \mathrm{K}\right)\end{array}$

\section{Effects of Creep in Concrete}

Creep of concrete may be a desirable or undesirable phenomenon, that is, its effects can be seen as significant and/or adverse.

On one hand, it is desirable as it imparts a degree of necessary ductility to the concrete before fracture. On the other hand, creep is often responsible for excessive deflections at service loads which can result in the instability of arch or shell structures, cracking; creep buckling of long columns and loss of pre-stress (Fanourakis, 1998).

Frequently, the results of creep are more damaging to non-loading bearing components associated with the structure such as window frames, cladding panels and partitions, than they are to the structure itself. The damaged structures are either shut down or undergo extensive repairs long before the end of their intended design life, resulting in significant economic consequences. Creep strain is therefore generally associated with its detrimental effects.

\section{Prediction Accuracy}

\section{The Prediction Of Creep Strain}

The magnitude of creep which is required for design purposes can be estimated at various levels. The choice of level depends on the type of structure and the quality of data available for the design in cases where only a rough estimate of the creep is required which is suitable only for approximate calculations, an estimate can be made on the basis of a few parameters such as relative humidity, age of concrete, member dimensions, etc. On the other extreme, in the case of deformation sensitive structures, estimates are based on comprehensive laboratory testing and mathematical and computer analyses. Ideally, a compromise has to be sought between the prediction procedure and the accuracy of results obtained.

At the design stage when the only information available is the comprehensive strength of the concrete, the general environmental conditions of exposure and the member sizes, the designer has to rely on a design code model to estimate and predict the extent and rate of creep strain.

\section{Elastic Modulus for Concrete}

Elastic modulus is the description of an object's tendency to be deformed elastically (i.e., nonpermanently) when a force is applied to it. The slope is the elastic deformation region of its stress-strain curve.

Short Term: Concrete is a non-linear, non-elastic material. Therefore, its elastic modulus is high due to its stiffness. It does not display a unique or constant value of elastic modulus as shown in Figure 2, and sustains permanent deformation on removal of load. When subjected to constant stress, concrete strains increase with time. It is also subject to changes of volume caused by shrinkage or swelling by temperature changes. 


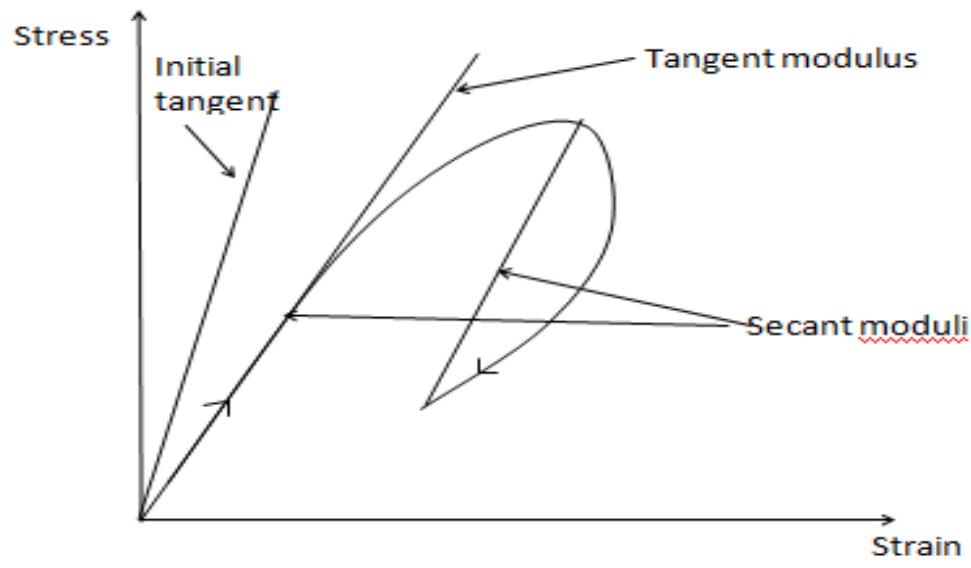

Fig. 2: Stress-strain curve for concrete showing various moduli

Notwithstanding the non-linearity, it is necessary to be able to quantify the relationship between stress and strain in order to obtain a realistic estimate of deformations. Various moduli are shown. There are; initial tangent modulus, a tangent modulus corresponding to a given stress level, a secant modulus and a chord modulus. The values of a number of these moduli are seen to depend on the reference stress levels. These are, in addition affected by rate of loading. The value used in design codes is generally a secant modulus corresponding to a specific rate of loading.

Long Term: In addition to the non-linearity displayed under short-term, concrete displays a time variant response to sustained loading. On unloading, recovery is neither instantaneous nor complete, but comprises an instantaneous portion followed over a period of time by a deferred recovery. At the end of this recovery, there remains a residual creep deformation. Another phenomenon which is related to long term creep is the relaxation of stress under sustained constant strain as shown in Figure 3.

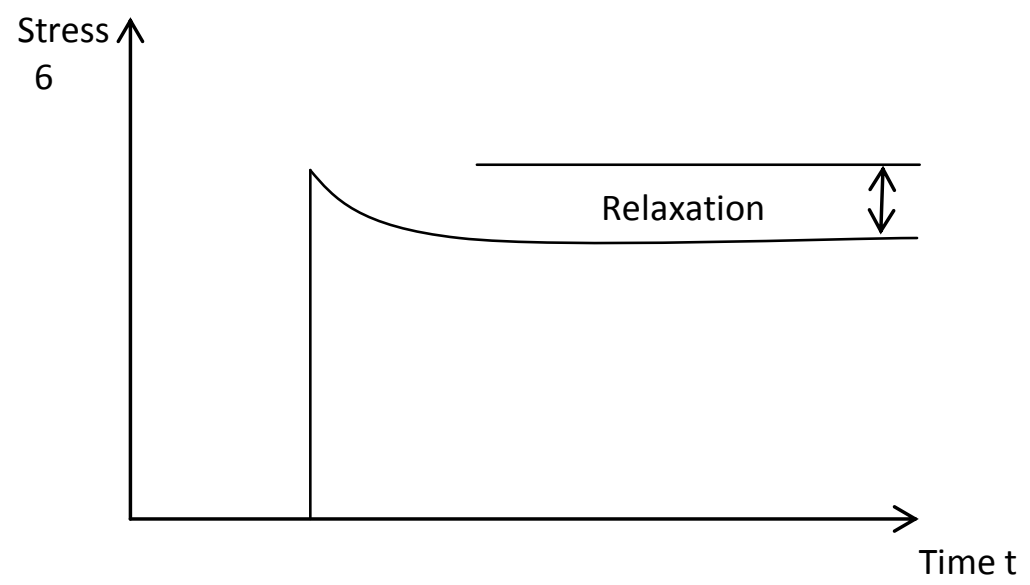

Fig. 3: Stress relaxation for long term elastic modulus

Even in the absence of applied loading, concrete is subject to deformation due to volume changes arising from changes in water content, from long-term chemical processes occurring within the certain paste mud from thermal dilation. The most significant of these changes is shrinkage, which is the reduction in concrete volume due to loss of water by evaporation or hydration of the cement or by carbonation.

\section{Design code models}

\section{Comparison Of Investigation From Different Sources}

The accuracy of commonly used internationally recommended type models that are used to predict creep strains without the need for laboratory tests are assessed. These empirically based models which vary widely in their techniques require certain intrinsic and/or extrinsic variables such as mixture proportion, material properties and age of loading as input. The models considered are listed in Table 1. 
Table 1: Models of prediction and factors accounted for

\begin{tabular}{|c|c|c|c|c|c|c|c|c|}
\hline & $\begin{array}{l}\text { FACTORS ACCOUNTED FOR BY DIFFERENT } \\
\text { PREDICTION METHODS }\end{array}$ & 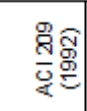 & 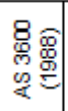 & 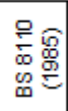 & $\begin{array}{l}\text { 은 } \\
\text { 息 } \\
\text { 号 }\end{array}$ & $\begin{array}{l}\text { 응 } \\
\text { 号 } \\
\text { 罗 }\end{array}$ & 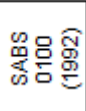 & 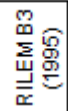 \\
\hline \multirow{9}{*}{ 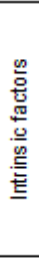 } & Aggregate type & & & & & & $\sqrt{ }$ & \\
\hline & AC Ratio & & & & & & & $\sqrt{ }$ \\
\hline & Air Content & & & & & & & \\
\hline & Cement Content & & & & $\sqrt{ }$ & $\sqrt{ }$ & & \\
\hline & Cement type & & & & & $\sqrt{ }$ & & $\sqrt{ }$ \\
\hline & Concrete density & & $\sqrt{ }$ & & & & & \\
\hline & Fine total aggregate ratio & $\sqrt{ }$ & & & & & & \\
\hline & Water / Cement ratio & $\sqrt{ }$ & & & & $\sqrt{ }$ & & $\sqrt{7}$ \\
\hline & Water content & & & & & & & j \\
\hline \multirow{11}{*}{ 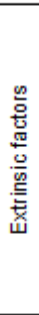 } & Age at first loading & $\sqrt{ }$ & J & $d$ & $\sqrt{ }$ & $d$ & L & L \\
\hline & Age of sample & & & & & & & 7 \\
\hline & Applied stress & $\sqrt{ }$ & d & $\sqrt{2}$ & $\sqrt{ }$ & $\sqrt{ }$ & $\sqrt{ }$ & $\sqrt{ }$ \\
\hline & Characteristic strength at Ioading & & & 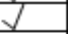 & & & $\sqrt{ }$ & \\
\hline & Cross sectional shape & & & & & & & $\sqrt{l}$ \\
\hline & Duration of loading & $1 /$ & d & & $\sqrt{ }$ & $\sqrt{1}$ & & j \\
\hline & Effective thickness & $\sqrt{7}$ & $\sqrt{2}$ & $\sqrt{ }$ & $\sqrt{7}$ & $\sqrt{ }$ & $\sqrt{ }$ & $\sqrt{2}$ \\
\hline & Elastic modulus at age of loading & & & $\sqrt{1}$ & & & $\sqrt{ }$ & $\sqrt{ }$ \\
\hline & Relative humidity & $\sqrt{ }$ & $\sqrt{1}$ & $y$ & $\sqrt{1}$ & $\sqrt{ }$ & $\sqrt{ }$ & $\sqrt{ }$ \\
\hline & Temperature & & & & & $\sqrt{2}$ & & $\sqrt{2}$ \\
\hline & Time drying commences & & & & & & & $\sqrt{ }$ \\
\hline
\end{tabular}

The table shows the factors accounted for by each model. With the exception of the RILEM model B3 (1995), the models considered derive from structural design codes of practice and express creep strain as the product of the elastic deformation of the concrete (at the time of loading) and the creep coefficient. A creep coefficient is directly entered in a load which is necessary to provide desired freedom to specified members. The creep coefficient accounts for the effect of one or more intrinsic and/or extrinsic variables.

\section{Analysis}

In order to provide a basis for comparing the creep strain of concrete with different strength and different applied loads, the results are presented in the form of specific creep, $\mathrm{C}_{\mathrm{c}}$, which is defined as creep strain per unit stress.

$$
C_{c}=\varepsilon_{c}(t) / \sigma
$$

All comparisons were on the basis of total creep (basic plus drying creep). As this investigation was of general nature, the specific intrinsic and extrinsic factors as well as differences in experimental techniques pertaining to different investigation were not compared.

The coefficient of variation of errors, $\omega_{j}$ was used to quantify the extent to which predicted specific creep values at different ages after loading (determine by a specific model) deviated from the values measured at the relevant ages on the specimens of a particular concrete mix. The more accurate the prediction, the lower the value of coefficient of variation of errors, $\omega_{\mathrm{j}}$.

\begin{tabular}{|c|c|c|c|c|c|c|c|}
\hline Data Source & 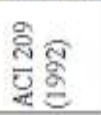 & $\begin{array}{l}8 \\
\text { m } 8 \\
0\end{array}$ & $\begin{array}{l}\frac{9}{\overline{0}} \overline{8} \\
0 \\
0\end{array}$ & $\begin{array}{l}\frac{1}{5} \delta \\
\frac{6}{5} \delta\end{array}$ & $\begin{array}{l}\hat{\mathrm{s}} \\
\mathrm{b} \\
\mathrm{s}\end{array}$ & $\stackrel{8}{8} \equiv$ & $\begin{array}{l}0 \\
25 \\
20 \\
20\end{array}$ \\
\hline Ballim (2000) & & & & & & 36.2 & 42.5 \\
\hline Fanourakis (1998) & 50.5 & 29.2 & 23.6 & 96.1 & 32.2 & 31.3 & 35.6 \\
\hline Gilbert (1988) & 32.2 & & & 27.1 & & & \\
\hline * Hansen and Mattock (1960) & 32.1 & & & & 11.9 & & 5.8 \\
\hline * Hummel et al (1962) & 46.2 & & & & 24.6 & & 15.3 \\
\hline - Keeton (1965) & 46.3 & & & & 37.9 & & 31.4 \\
\hline * L' Hermite and Mamillan (1970) & 62.5 & & & & 15.2 & & 20.6 \\
\hline * L' Hermite and Mamillan (1965) & 55.8 & & & & 25.5 & & 14 \\
\hline * Maity and Meyes (1970) & 45.9 & & & & 83.7 & & 62.8 \\
\hline * Mc Donald (1975) & 40.4 & & & & 38.9 & & 10.9 \\
\hline * Me Donald et al (1988) & 71.4 & 22.4 & & 72.1 & & & \\
\hline * Missiossian and Gamble (1972) & 71.7 & & & & 30.8 & & 11.3 \\
\hline Rogowsky and Soleymani (2003) & & & & 54.8 & 46.2 & & \\
\hline * Rostasy et al (1972) & 20.9 & & & & 14.8 & & 6.5 \\
\hline * Russel and Burg (1993) & 41.2 & & & & 19.1 & & 10.7 \\
\hline * Troxell et al (1959) & 33 & & & & 7.9 & & 5.9 \\
\hline Yorket al $(1970)$ & 42.1 & & & & 45.1 & & 5.8 \\
\hline Overall, $\square$ & 46.1 & 25.3 & 23.6 & 62.5 & 30.9 & 33.8 & 19.9 \\
\hline
\end{tabular}


The data source marked asterisk $(*)$ indicates data from RILEM Data Bank.

The accuracy of the above mentioned code type prediction methods was assessed by comparing the accuracy of predictions from separate research projects.

Ballim (2000) considered the accuracy of the SABS0100 model. The work of Fanowrakis (1998) comprised the measurement of creep on concretes of different strengths, grades made with three commonly aggregate types. The accuracy predictions made by the ACI 209 (1992), CEB-FIP was introduced in the investigation by Gilbert (1988). McDonald et al (1988) assessed the accuracy of a number of creep prediction method.

The recent research by Rogowsky and Soleymani (2003) assessed the accuracy of 1990 model of CEBFIP. In the case of the RILEM model B3 (1995), comparisons were made between total creep prediction for the RILEM B3 (1995), the ACI 209 (1992) and the CEB-FIP (1990) methods.

\section{Results} Table 2.

From the different investigations, the coefficients of variations for the code type models are given in

The BS8110 (1985) model was excluded from the analysis as comparative predictions were not found. From Figure 1 and Table 2, it is evident that the RILEM model B3 is the most accurate of the prediction models, yielding an over all coefficient $\omega_{\text {all }}$ of 19.9. The CEB-FIP (1978) was the least accurate with $\omega_{\text {all }}=62.5$. In addition, the lowest coefficient of variation $\omega_{j}=8.5$ was yielded by the RILEM model B3 in two different investigations.

In view of the fact that at least fourteen data sets were used in the comparisons in the case of RILEM model B3 (1995), CEB-FIP (1990) and ACI 209 (1992) models, further emphasis is justifiably placed on the accuracy of these models. The overall coefficients of variations, $\omega_{\text {all }}$ and minimum coefficient of variation of error, $\omega_{\min }$ increases in the order RILEM B3 (1995), CEP-FIP (1990) and ACI 209 (1992).

Furthermore, it is evident from Table 2, that the CEB-FIP (1990) model is more accurate that its predecessor CEB-FIP (1978) model. This trend was also evident in the work of Fanourakis (1998).

\section{Conclusion}

This paper assessed and predicted creep deformation in concrete using the accuracy of some design code models. The RILEM model B3 appeared to provide the most accurate predictions with $\omega_{\mathrm{j}}=19.9$ while the CEB-FIP model was found to be least accurate with coefficient of variation, $\omega_{j}=62.5$. The higher the accuracy of the prediction, the lower the value of $\omega_{\mathrm{j}}$.

Detailed investigation on the accurate of prediction using AS 3600 (1988), BS 8110 (1985) and SAB 0100 (1992) methods is recommended in order to determine the accuracy of these methods when applied to more data sets.

\section{References}

[1] American Concrete Institute (ACI) (1992). ACI Committee 209, Subcommittee II. Prediction of Creep, Shrinkage and Temperature Effects in Concrete Structures Report ACI 209 R92, District, pp 1-12.

[2] AS 3600 (1988). Concrete structures: AS 3600 Standard Association of Australia, North Sydney pp 8-14.

[3] BS 8110 (1985). Structural use of Concrete, Part 2, Code of Practice for Design and Construction, London, British Structural Institution.

[4] CEB-FIP (1978). Comite' Europeen du Be'ton-Federation Internationale De la Precontrainte, International System of Unified Standard Code of Practice for Structures, Vol II. CEB-FIP Model Code for Concrete Structures. 3rd ed Lausanne pp 56, $331-344$.

[5] CEB-FIP (1990). CEB-FIP Model Code. First Draft, Lausanne Information Bulletin No. 195, pp 2-3, 28, 40.

[6] Fanourakis, G. C. (1998). The Influence of Aggregate Stiffness on the Measured and Predicted Creep Behavior of Concrete, M.Sc.(Eng) Dissertation, University of Witwatersrand, Johannesburg.

[7] RILEM Model B3 (1995). Creep and Shrinkage Model for Analysis and Design of Concrete structures: Model B3, Draft RILEM Recommendations. Materials and Structures. Vol. 28, pp 357-365, 415-430, 488-495. Vol. 29 (1996), pp 126.

[8] SABA 0100 (1992). Code of Practice for the Structural use of Concrete, Part 1, \& 2, Part 1: Design, Part 2: Materials. Pretoria, South African Bureau of Standards. 